\title{
Percepción del profesional de salud sobre los estudiantes en la práctica profesional. Carrera de Obstetricia, Instituto Dr. Andrés Barbero de la Universidad Nacional de Asunción
}

\author{
Elena María Rodríguez Oliveira, Esperanza Paniagua
}

\begin{abstract}
Resumen
Introducción: Una relación necesaria entre la teoría y la práctica ha sido un común denominador en la formación del estudiante universitario, lo cual constituye una exigencia para el desarrollo de un proyecto educativo de calidad. La práctica profesional es el ámbito donde el estudiante articula los conocimientos teóricos, y el valor humanizado en la atención. La participación de estudiantes en los servicios de salud es un potencial para todas las universidades, en la cual debe demostrar su capacidad protagónica y transformadora definida como estrategia entre las instituciones de educación y los servicios de salud para transformar la sociedad a través de la creación de la cultura de la salud, razón por la cual es fundamental involucrar a los centros asistenciales a ser partícipes de la formación del estudiante de la Carrera de Obstetricia. En ese sentido el profesional de salud alude los beneficios que brindan la presencia y participación activa del estudiante en los centros asistenciales, como mano de obra calificada para el mundo laboral y ser colabores al logro de los objetivos trazados por la institución de salud.
\end{abstract}

Objetivo: Identificar Percepción del profesional de salud sobre los estudiantes en la práctica profesional. Carrera de Obstetricia. Instituto Dr. Andrés Barbero Universidad Nacional de Asunción.

Material y Método: Tipo de estudio Observacional, Descriptivo de corte transversal, enfoque cuantitativo. Se realizó en Hospitales de referencia para la atención materna ubicada en el Departamento Central Hospital de Clínica Cátedra de Gineco-Obstetricia de la Facultad de Ciencias Médicas de la UNA Hospital Materno Infantil Fernando de la Mora, Hospital Materno Infantil Mariano Roque Alonso y Cordillera Hospital Regional de Caacupé. El universo constituyó 150 profesionales de salud, Se seleccionaron 91 profesionales de la salud del Consultorio de Salud Sexual y Reproductiva, Urgencias Gineco Obstétrica, Neonatología, Puerperio, Área toco quirúrgico, muestreo no probalístico por conveniencia, criterio de inclusión profesional médico gineco

\footnotetext{
1. Instituto Dr. Andrés Barbero, Universidad Nacional de Asunción, Paraguay.

Trabajo Final de Investigación presentada al Instituto Dr. Andrés Barbero, Universidad Nacional de Asunción, como requisito para la obtención de Diploma de Especialista en Investigación en Salud. E-mail: elenamariapy@hotmail.com
}

DOI: 10.26885/rcei.foro.2017.146 
obstetra, obstetra, enfermera; método la encuesta, técnica la entrevista y como instrumento un cuestionario con preguntas abiertas, cerradas y múltiple. Los datos recabados fueron cargados en una planilla electrónica Microsoft Office Excel 2010, se depuró y se analizó con estadística descriptiva a través del software Estadístico Epi Info 7.2. A partir de los resultados se construyeron tablas y gráficos para representar los mismos. La percepción positiva se consideró en base a una escala del $75 \%$ del total de ítems para la medición de esta variable. La participación del sujeto de estudio fue anónima y voluntaria, se mantuvo la confidencialidad de los resultados, respetando los principios éticos de la investigación.

Resultados: La percepción del profesional de la salud sobre las características generales del estudiante en cuanto a que carrera realiza la práctica profesional en el hospital 56\% carrera de Obstetricia y otras, $44 \%$ carrera de Obstetricia IAB-UNA; las actividades que realizan los estudiantes $62 \%$ atención directa del trabajo de parto, parto y puerperio; 15\% atención al neonato, 13\% atención integral de la mujer, $10 \%$ atención pre natal; el profesional de la salud diferencia al estudiante de carrera de Obstetricia IAB-UNA referente a: 36\% valores, $25 \%$ conocimiento teórico, 13\% habilidad, 13\% acompañamiento por el instructor. El profesional de salud percibe favorablemente (82\%) sobre la apariencia personal, comunicación interpersonal y asistencia puntual al campo de práctica del estudiante. Percepción del profesional de salud sobre el estudiante en cuanto a: bioseguridad 57\%, principios éticos $43 \%$. Referente al desempeño del estudiante de la carrera de Obstetricia IAB-UNA el profesional de salud percibe $34 \%$ mano de obra calificada, 33\% atención calificada (capacidad resolutiva) y humanizada (necesidades multidimensional bilógico, psicológico y conductual del ser humano). Los profesionales de la salud poseen percepción positiva (75\%) y negativa (25\%) sobre estudiantes de la Carrera de Obstetricia del IAB UNA en la práctica profesional.

Conclusiones: La percepción del profesional de la salud sobre las características generales del estudiante casi la totalidad reconoce la carrera que realiza la práctica profesional en el hospital durante su desempeño, poco más de la mitad del profesional de la salud percibe que las actividades que realizan los estudiantes son acordes a su formación; se diferencia al estudiante de carrera de Obstetricia IAB-UNA por los valores humanos percibidos (respeto, honestidad, humildad, solidaridad).

Casi la totalidad del profesional de salud percibe favorablemente la apariencia personal, comunicación interpersonal y asistencia puntual al campo de práctica del estudiante.

Casi la totalidad del profesional de salud percibe favorablemente sobre el estudiante, referente al cumplimiento de las normas de bioseguridad y principios éticos.

Casi la totalidad del profesional de salud percibe favorablemente sobre el estudiante, referente a mano de obra calificada, atención calificada y humanizada. 
Se concluye que un elevado porcentaje del profesional de la salud posee percepción positiva sobre los estudiantes de la Carrera de Obstetricia del IAB UNA en la práctica profesional.

Palabras clave: percepción, práctica profesional, estudiante universitario.

\section{Referencias}

Beca, J. P., Gómez, M. I., Browne, F. \& Browne, J. (2011). Los estudiantes de medicina como parte del equipo de salud. Rev Med. Chile.

Ceballos, E. (2012). Humanización de la atención en salud Facultad de Medicina. Salud Pública de Medellin. Recuperado de http://bdigital.ces. edu.co:8080/repositorio/bitstream/10946/1675/2/Humanizacion_ servicios_salud.pdf

Soto Fuentes, P. \& García, M. A. (2011). Impacto de un modelo de integración docente asistencial en la formación profesional y el campo clínico. Ciencia y Enfermería XVII. 